\title{
Marie Gagnier, Console-moi
}

\section{Lucie Picard}

\section{(2) OpenEdition}

\section{Journals}

\section{Édition électronique}

URL : https://journals.openedition.org/studifrancesi/38492

DOI : $10.4000 /$ studifrancesi.38492

ISSN : 2427-5856

\section{Éditeur}

Rosenberg \& Sellier

\section{Édition imprimée}

Date de publication : 15 décembre 2004

Pagination : 664-665

ISSN : 0039-2944

\section{Référence électronique}

Lucie Picard, « Marie Gagnier, Console-moi », Studi Francesi [En ligne], 144 (XLVIII | III) | 2004, mis en ligne le 30 novembre 2015, consulté le 08 mai 2021. URL : http://journals.openedition.org/ studifrancesi/38492 ; DOI : https://doi.org/10.4000/studifrancesi.38492

\section{Ce document a été généré automatiquement le 8 mai 2021.}

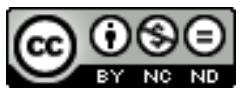

Studi Francesi è distribuita con Licenza Creative Commons Attribuzione - Non commerciale - Non opere derivate 4.0 Internazionale. 


\title{
Marie Gagnier, Console-moi
}

\author{
Lucie Picard
}

\section{RÉFÉRENCE}

MARIE GAGNIER, Console-moi, Montréal, Boréal, 2003, pp. 319.

1 Centré sur la thématique de la douleur qui morcelle et déstructure l'être, Console-moi, troisième roman de $\mathrm{M}$. Gagnier, offre une multitude de portraits et de situations apparemment sans liens entre eux, lesquels s'emboîtent pourtant au fur et à mesure que progresse la narration pour former un tout à la fois complexe et cohérent. L'unité de l'ensemble est construite autour du personnage de Gabriel, jeune homme qui se débat avec une existence étriquée, rendue plus amère encore par la conscience du hiatus entre la réalité et les histoires fabuleuses dont son père, veuf et alcoolique, a nourri son enfance; autour d'une situation, en l'occurrence une succession de morts suspectes qui frappe des villages côtiers du Québec et du Nouveau-Brunswick au cours de l'été 1963; enfin, autour de la métaphore du vitrail, lieu d'une mise en abyme de l'œuvre.

2 Porté par l'écriture à la fois sobre et vibrante de Gagnier, Console-moi explore les voies opposées de l'espoir qui procède pas à pas et de la désespérance auto-destructrice empruntées par les différents personnages, auxquels l'auteur confère un étonnant «effet d'humanité». Outre ses qualités de construction, de rythme et d'élaboration de personnages, ainsi que l'usage tout à fait inédit que fait l'auteur du motif du tueur en série, le roman présente un intérêt supplémentaire pour les lecteurs étrangers, leur permettant de découvrir deux francophonies canadiennes dans leur rencontre et leurs différences (notamment linguistiques): celle du Québec et celle de l'Acadie. 